Document downloaded from:

http://hdl.handle.net/10251/155016

This paper must be cited as:

Reid, LO.; Dántola, ML.; Petroselli, G.; Erra-Balsells, R.; Miranda Alonso, MÁ.; Lhiaubet, VL.; Thomas, AH. (2019). Chemical Modifications of Globular Proteins Phototriggered by an Endogenous Photosensitizer. Chemical Research in Toxicology. 32(11):2250-2259. https://doi.org/10.1021/acs.chemrestox.9b00286

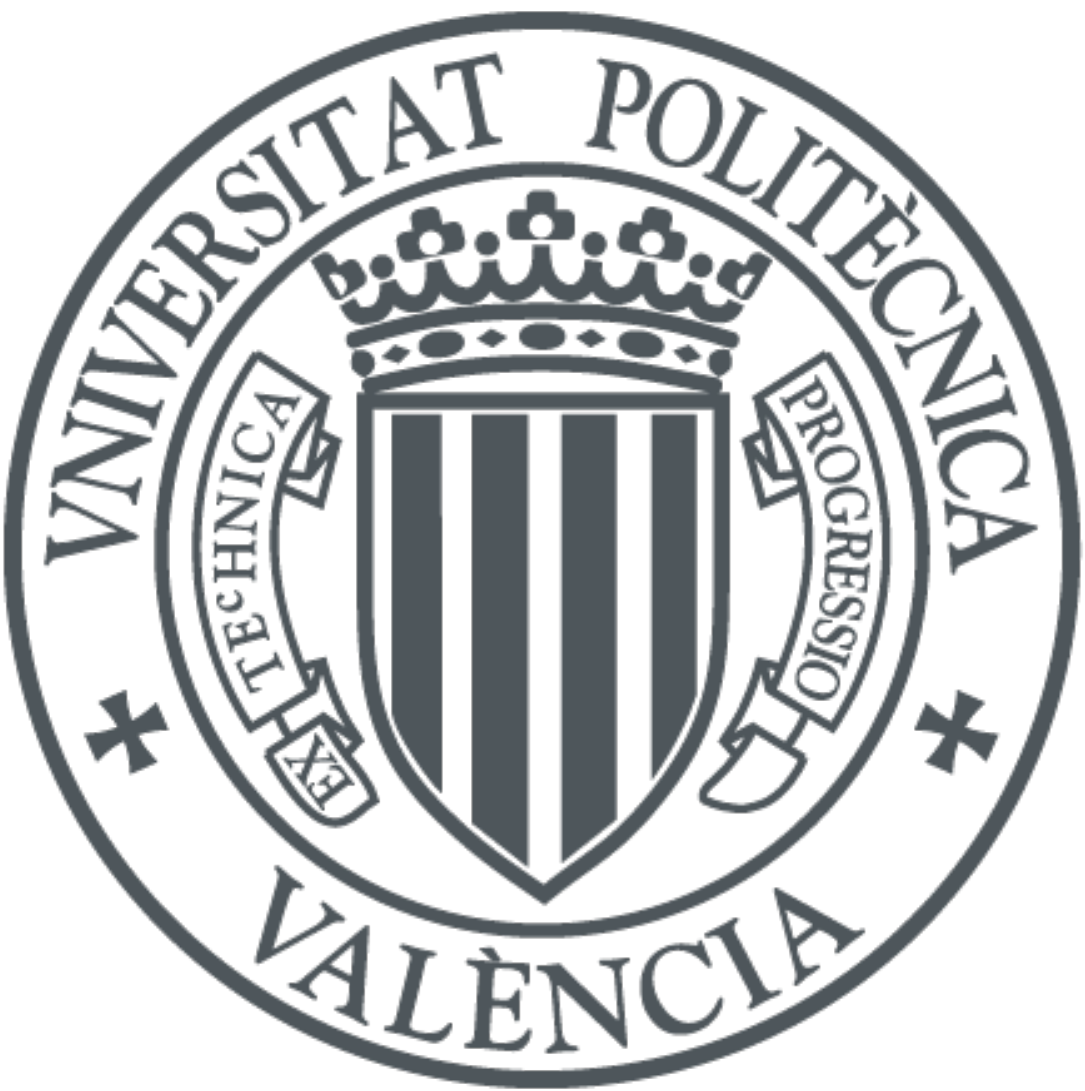

The final publication is available at

https://doi.org/10.1021/acs.chemrestox.9b00286

Copyright American Chemical Society

Additional Information 


\section{Chemical modifications of globular proteins phototriggered by an endogenous photosensitizer}

Lara O. Reid, ${ }^{1}$ M. Laura Dántola, ${ }^{1}$ Gabriela Petroselli, ${ }^{2}$ Rosa Erra-Balsells, ${ }^{2}$ Miguel A. Miranda, ${ }^{3}$ Virginie Lhiaubet-Vallet ${ }^{3, *}$, Andrés H. Thomas ${ }^{1, *}$

1 Instituto de Investigaciones Fisicoquímicas Teóricas y Aplicadas (INIFTA), Departamento de Química, Facultad de Ciencias Exactas, Universidad Nacional de La Plata, CCT La Plata-CONICET. Casilla de Correo 16, Sucursal 4, (1900) La Plata, Argentina.

${ }^{2}$ CIHIDECAR - CONICET, Departamento de Química Orgánica, Facultad de Ciencias Exactas y Naturales, Universidad de Buenos Aires, Pabellón 2, 3p, Ciudad Universitaria, 1428 - Buenos Aires, Argentina.

${ }^{3}$ Instituto de Tecnología Química, Universitat Politècnica de València - Consejo Superior de Investigaciones Científicas, Avenida de los Naranjos s/n, 46022 Valencia, España.

*Corresponding authors

Dr. Andrés H. Thomas

E-mail: athomas@inifta.unlp.edu.ar

Postal Address: C.C. 16, Sucursal 4, (B1904DPI), La Plata, Argentina

Phone: +542214257430 int.189

Fax: +54 2214254642

Dr. Virginie Lhiaubet-Vallet

E-mail: lvirgini@itq.upv.es

Postal Address: Instituto de Tecnología Química (UPV-CSIC), Avda de los Naranjos, s/n, 46022, Valencia, Spain

Phone: 963877815 , ext 77815

Fax: 963873409 


\begin{abstract}
The main goal of the present work was to investigate the damages photoinduced by pterin (Ptr), an endogenous photosensitizer present in human skin under pathological conditions, on a globular protein such as ubiquitin (Ub). A particular attention has been paid on the formation of covalent adducts between Ptr and the protein that can behave as photoantigen and provoke an immune system response. Here, a multifaceted approach including UV/visible spectrophotometry, fluorescence spectroscopy, electrophoresis, size exclusion chromatography and mass spectrometry is used to establish the Ub changes triggered by UVA irradiation in the presence of Ptr. Under anaerobic conditions, the only reaction corresponds to the formation of a covalently bound Ptr-Ub adduct that retains the spectroscopic properties of the free photosensitizer. A more complex scheme is observed in air-equilibrated solutions with the occurrence of three different processes ie. formation of a Ptr-Ub adduct, dimerization and fragmentation of the protein.
\end{abstract}




\section{Introduction}

Photoallergy is a photosensitivity disorder associated with a modified ability of the skin to react to the combined effect of drugs and sunlight. It results from the conversion of xenobiotics into antigens after their photochemical activation in biological systems. The molecular origin of this disease has been attributed to covalent conjugation of proteins with photosensitizing drugs, photochemical intermediates or photoproducts (generally referred to as haptens); the resulting modified proteins can definitively act as antigens provoking the immune system response. ${ }^{1}$ A large number of exogenous photoallergenic agents have been investigated. ${ }^{2,3,4,5}$ However, up to now the potential role of some endogenous compounds as photoallergens has not been fully established.

Pterins, a family of heterocyclic compounds are present in biological systems in multiple forms and play different roles ranging from pigments to enzymatic cofactors for numerous redox and one-carbon transfer reactions. ${ }^{6,7}$ Pterins can exist in living systems in different redox states and may be classified into three groups according to this property: fully oxidized (or aromatic) pterins, dihydro and tetrahydro derivatives. These derivatives are present in human epidermis as 5,6,7,8-tetrahydrobiopterin $\left(\mathrm{H}_{4} \mathrm{Bip}\right)$, which is an essential cofactor for aromatic amino acid hydroxylases ${ }^{8}$ and participates in the regulation of melanin biosynthesis. ${ }^{9}$ They are of particular importance in vitiligo, a skin disorder characterized by a defective protection against UV radiation due to the acquired loss of constitutional pigmentation. ${ }^{10}$ In this disease, the $\mathrm{H}_{4} \mathrm{Bip}$ metabolism is altered ${ }^{11}$ and dihydro and oxidized pterin derivatives accumulate in the affected tissues at concentrations, which are significantly higher than those reported for healthy cells. ${ }^{12}$ Moreover, it can be assumed that pterins can reach any cellular compartment since pterins can freely cross phospholipid membranes. ${ }^{13}$ 
The photochemistry of pterins is relevant to understand the harmful effects of radiation on skin, and is of particular interest in depigmentation disorders. Oxidized pterins are photochemically reactive in aqueous solutions and, upon UV-A excitation, they can fluoresce, produce reactive oxygen species (ROS) ${ }^{14,15,16}$ and, photosensitize the oxidation of different biomolecules such as DNA and proteins. ${ }^{17,18,19}$ In the case of the former, pterin (Ptr, Figure 1), the parent and unsubstituted compound of oxidized pterins, has demonstrated its photooxidative potential giving rise to the formation of the characteristic guanine damages. ${ }^{17}$ Interestingly, upon UV-A irradiation Ptr also reacts with thymine (Thy) yielding different products, whose distribution depends on the concentration of molecular oxygen $\left(\mathrm{O}_{2}\right) .{ }^{20}$ This process is initiated by an electron transfer from the nucleobase to the triplet excited state of $\mathrm{P} \operatorname{tr}\left({ }^{3} \mathrm{Ptr} *\right)$, yielding the Ptr radical anion $\left(\mathrm{Ptr}^{\bullet-}\right)$ and the Thy radical cation $\left(\mathrm{Thy}^{\bullet+}\right)$. In the absence of $\mathrm{O}_{2}$, the $\mathrm{Ptr}^{\bullet-}$ reacts with Thy ${ }^{\bullet+}$ yielding an adduct Ptr-Thy in which the photosensitizer is covalently linked to the Thy moiety. ${ }^{20,21}$ On the other hand, in the presence of $\mathrm{O}_{2}$, the photoadduct formation is avoided because $\mathrm{Ptr}^{\bullet-}$ rapidly transfers an electron to $\mathrm{O}_{2}$ to regenerate $\mathrm{Ptr}$ and form superoxide radical anion $\left(\mathrm{O}_{2}{ }^{\bullet-}\right)$.

In addition, pterins photoinduce chemical and functional alterations in proteins. ${ }^{18}$ It has been reported that different pterin derivatives are able to photoinduce the inactivation of tyrosinase, an essential enzyme in the melanin biosynthesis. ${ }^{22}$ Studies performed with human serum albumin (HSA) revealed that Ptr photosensitizes the oxidation and the oligomerization of HSA. ${ }^{23}$ Several amino acids are oxidized in these processes and the oligomerization is mediated by the formation of tyrosine dimers $\left(\operatorname{Tyr}_{2}\right) \cdot{ }^{23}$ 


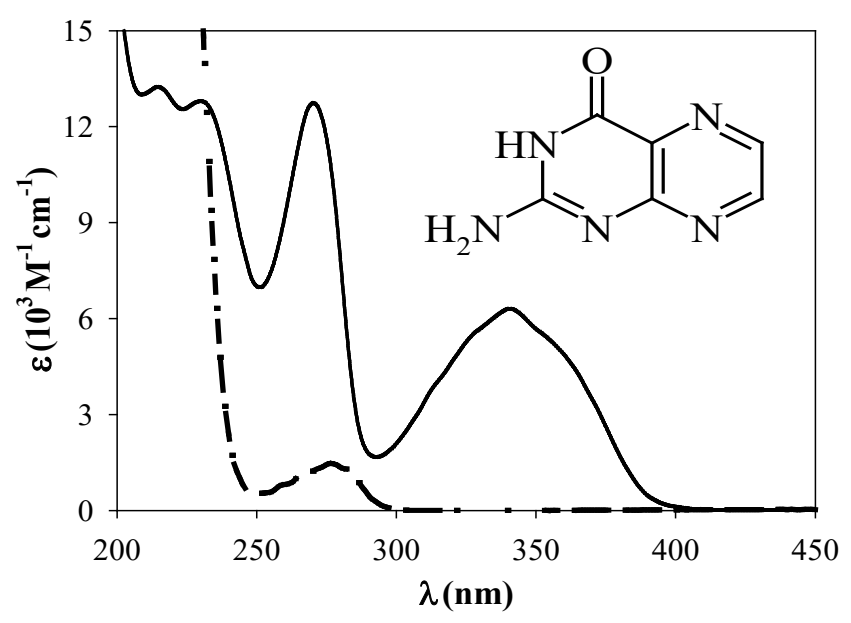

Figure 1. Absorption spectra of Ub (dashed line) and Ptr (solid line) in neutral and slightly acidic aqueous solutions. Molecular structure of Ptr.

With this background, the goal of the present work is to investigate if Ptr is able to generate photoadducts with proteins, which would yield modified skin proteins that, in turn, might act as antigens provoking the immune system response. In this study we have used ubiquitin $(\mathrm{Ub})$, as a model protein. Indeed, this small regulatory protein of ca. 8.5 $\mathrm{kDa}$ present in all eukaryotic cells exhibits interesting characteristics for our study as it has only one Tyrosine (Tyr) and lacks Tryptophan, ${ }^{24,25}$ and it has already been used successfully for investigating covalent binding by means of mass spectrometry. $5,26,27$ Thus, aqueous solutions of Ptr and Ub were exposed to UV-A radiation and the resulting treated solutions were analyzed by a multifaceted approach combining UV/visible spectrophotometry, fluorescence spectroscopy, electrophoresis, size exclusion chromatography and mass spectrometry. It is noteworthy that the Ptr concentrations used were of the same order of magnitude as those found in human skin affected by vitiligo. ${ }^{12}$

\section{Experimental Section}




\section{General}

Chemicals. Pterin (Ptr, purity $>$ 99\%, Schircks Laboratories, Switzerland) and ubiquitin from bovine erythrocytes, whose sequence is identical to the human protein, (SigmaAldrich, St. Louis, MO) were used without further purification after checking for impurities by HPLC. Sodium dodecyl sulfate (SDS, $99 \%$ ), glycerol, 2mercaptoethanol, bromophenol blue, glycine (Gly, $>99 \%$ titration), ammonium

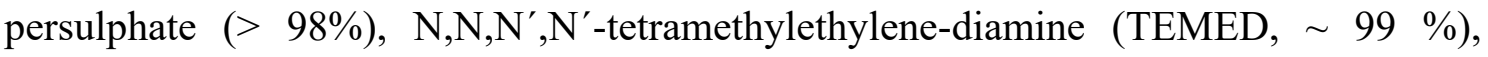
Cytochrome c (Cyt) from horse heart, E-3,5-dimethoxy-4-hydroxycinnamic acid (E-SA), -cyano-4-hydroxycinnamic acid (CHCA), bradykinin (1-7), insulin, angiotensin I and II and guanidine chloride were provided by Sigma Aldrich. Methanol was provided by Laboratorios Cicarelli. Trifluoroacetic acid (TFA) was provided by Merck. Acetic acid was provided by Anedra. Coomassie Brilliant Blue $G$ was provided by Fluka. Acrylamide, $\mathrm{N}^{\prime}, \mathrm{N}^{\prime}$-methylene-bis-acrylamide and trishydroxymethylaminomethane (Tris) were purchased by Genbiotech. $\mathrm{NaCl}$ and acetonitrile were provided by J. T. Baker. Aqueous solutions were prepared using ultrapure water from Milli- ${ }^{\circledR}$ purification system (Millipore Corporation, USA).

Measurements of $\mathrm{pH}$. The $\mathrm{pH}$ measurements were performed using a $\mathrm{pH}-$ meter sensION+ pH31 GLP combined with a pH electrode 5010T (Hach) or microelectrode XC161 (Radiometer Analytical). The $\mathrm{pH}$ of the aqueous solutions was adjusted by adding drops of $\mathrm{HCl}$ and $\mathrm{NaOH}$ solutions from a micropipette. The concentration of the acid and the base used for this purpose ranged from 0.1 to $2 \mathrm{M}$.

UV/vis analysis. Electronic absorption spectra were recorded on a Shimadzu UV-1800 spectrophotometer. Measurements were made using quartz cells of 0.4 or $1 \mathrm{~cm}$ optical pathlength. The absorption spectra of the solutions were recorded at regular intervals of irradiation time. 


\section{Steady-state irradiation}

The continuous irradiation of the solutions containing Ptr and Ub were carried out in quartz cells ( $0.4 \mathrm{~cm}$ optical path length) at room temperature, using two Rayonet RPR 3500 lamps (Southern N.E. Ultraviolet Co.) with emission centered at $350 \mathrm{~nm}$ (bandwidth (fwhm) 20 nm). The experiments were performed in the presence and in the absence of dissolved $\mathrm{O}_{2}$. Experiments with air-equilibrated solutions were carried out in open quartz cells without bubbling, whereas argon saturated solutions were obtained by bubbling for 20 min with this gas, previously water saturated (Linde, purity $>99.998 \%$ ).

Aberchrome 540 (Aberchromics Ltd.) was used as an actinometer for the measurement of the incident photon flux densitity $\left(q_{n, p}^{0, V}\right)$ at the excitation wavelength, which is the amount of incident photons per time interval $\left(q_{n, p}^{0}\right)$ and divided by the volume of the sample. ${ }^{28}$ The method for the determination of $q_{n, p}^{0, V}$ has been described in detail elsewhere. ${ }^{29}$ The value of $q_{n, p}^{0, V}$ measured for the radiation source was $5.0( \pm 0.4) \times 10^{-5}$ Einstein $\mathrm{L}^{-1} \mathrm{~s}^{-1}$. Taking into account that the lamp emits quasi-monochromatic radiation, $q_{n, p}^{0, V}$ value was converted into the UV irradiance of the lamp $\left(E_{U V}^{L}\right)$ with the equation 1.

$$
E_{U V}^{L}=q_{n, p}^{0, V} N_{A} h v \frac{V}{S}
$$

where $N_{A} h v$ is the energy of a mol of photons emitted by the lamp and $\mathrm{V}$ and $\mathrm{S}$ are, respectively, the volume and the area exposed to irradiation of the cell used. A value of $71( \pm 6) W \mathrm{~m}^{-2}$ was obtained for $E_{U V}^{L}$. For each experiment, the UV dose (energy density) in $\mathrm{J} \mathrm{cm}^{-2}$ was calculated with equation 2

$$
\text { dose }=E_{U V}^{L} t_{i} 10^{-4}
$$

where $t_{i}$ is the irradiation time in $\mathrm{s}$. 


\section{High-performance liquid chromatography (HPLC).}

A Prominence equipment from Shimadzu (solvent delivery module LC-20AT, online degasser DGU-20A5, communications bus module CBM-20, auto sampler SIL-20A HT, column oven CTO-10AS VP, photodiode array (PDA) detector SPD-M20A and fluorescence (FL) detector RF-20A) was employed for monitoring the photochemical processes. A BioSep- SEC-s2000 column (silica, 300 x $7.8 \mathrm{~mm}, 14.5 \mu \mathrm{m}$, Phenomenex) was used for product separation. $10 \mathrm{mM}$ Tris- $\mathrm{HCl}, 150 \mathrm{mM} \mathrm{NaCl}(\mathrm{pH}$ 5.5) was used as the mobile phase.

Preparative chromatography. The protein fraction was separated from free Ptr using guanidine chloride and disposable Sephadex G-25 columns (PD-10, Amersham Pharmacie Biotech, UK).

\section{Fluorescence spectroscopy}

Fluorescence measurements were performed using a Single-Photon-Counting equipment FL3 TCSPC-SP (Horiba Jobin Yvon). The equipment has been previously described in detail. ${ }^{30}$

Steady-state experiments. The sample solution in a quartz cell was irradiated with a $450 \mathrm{~W}$ Xenon source through an excitation monochromator. The fluorescence, after passing through an emission monochromator, was registered at $90^{\circ}$ with respect to the incident beam using a room-temperature R928P detector. Corrected fluorescence spectra obtained by excitation at $350 \mathrm{~nm}$ were recorded in the range $370-600 \mathrm{~nm}$. The excitation spectra were recorded between 240 and $420 \mathrm{~nm}$, monitoring the fluorescence intensity at $440 \mathrm{~nm}$. Time-resolved experiments. NanoLED source (maximum at $341 \mathrm{~nm}$ ) was used for excitation. The emitted photons, after passing through the iHR320 monochromator, were detected by a TBX-04 detector connected to a TBX-PS power supply and counted by a 
FluoroHub-B module, controlled using the DataStation measurement control software application. The selected counting time window for the measurements reported in this study was $0-200 \mathrm{~ns}$.

\section{Electrophoresis}

Protein damage was evaluated by sodium dodecyl sulfate polyacrylamide gel electrophoresis (SDS-PAGE). Samples of protein solutions were boiled for 5 minutes in a $0.06 \mathrm{M}$ Tris- $\mathrm{HCl}$ ( $\mathrm{pH}$ 6.8) solution containing 2\% SDS, 10\% glycerol, 1\% 2mercaptoethanol (as reducing agent) and 0.02\% bromophenol blue (as a tracking dye). Acrylamide (4\%) stacking gel, $20 \%$ acrylamide resolving gel and running buffer containing $25 \mathrm{mM}$ Tris, $192 \mathrm{mM}$ Gly and 0.1\% SDS, pH 8.3 were used. Electrophoresis was performed at $120 \mathrm{~V}$ during $125 \mathrm{~min}$. Gels were stained with $0.1 \%$ Coomassie Brilliant Blue $\mathrm{G}$ and destained with a solution of methanol and acetic acid during $1 \mathrm{~h}$.

\section{MALDI mass spectrometry}

Irradiated samples were analyzed by ultraviolet matrix assisted laser desorptionionization mass spectrometry (MALDI-MS) analysis performed on the Bruker Ultraflex Daltonics TOF/TOF mass spectrometer. Mass spectra were acquired in linear positive mode and with the LIFT device in the MS/MS mode. External mass calibration was made using commercial peptides (bradykinin (1-7) (757.39916), angiotensin II (1046.54180), angiotensin I (1296.684), insulin (5734.52000) and cytochrome C (12360.97400). E-SA and E-CHCA were used as MALDI matrices. Sample solutions were spotted on a MTP 384 target plate polished steel from Bruker Daltonics (Germany). For MALDI-MS matrix solutions were prepared as E-SA $(1 \mathrm{mg} / \mathrm{ml})$ and E-CHCA $(1 \mathrm{mg} / \mathrm{mL})$ in $\mathrm{MeCN}$ : TFA $0.1 \%$ 50:50 (v/v). For MALDI-MS experiments sandwich method was used according to 
Nonami et al. ${ }^{31}$ loading successively $0.5 \mu \mathrm{L}$ of matrix solution, analyte solution and matrix solution (x2) after drying each layer at normal atmosphere and room temperature. The matrix to analyte ratio was $3: 1(\mathrm{v} / \mathrm{v})$ and the matrix and analyte solution loading sequence was: i) matrix, ii) analyte, iii) matrix, iv) matrix. Desorption/ionization was obtained by using the frequency-tripled Nd:YAG laser $(355 \mathrm{~nm})$. Experiments were performed using firstly the full range setting for laser firing position in order to select the optimal position for data collection, and secondly fixing the laser firing position in the sample sweet spots. The laser power was adjusted to obtain high signal-to-noise ratio $(\mathrm{S} / \mathrm{N})$ while ensuring minimal fragmentation of the parent ions and each mass spectrum was generated by averaging 100 lasers pulses per spot. Spectra were obtained and analyzed with the programs FlexControl and FlexAnalysis, respectively.

\section{Nano liquid chromatography mass spectrometry analysis (nano LC-MS)}

Samples were also analyzed by nanoLC-MS in a Thermo Scientific QExactive Mass Spectrometer coupled to a nanoHPLC EASY-nLC 1000 (Thermo Scientific). For the LC-MS analysis, samples were loaded onto a reverse phase column $(\mathrm{C} 18,2 \mu \mathrm{m}, 100 \mathrm{~A}$, $50 \mu \mathrm{m}$ x $150 \mathrm{~mm}$ ) Easy-Spray Column PepMap RSLC (P/N ES801)) suitable for separating protein with a high degree of resolution. The flow rate used for the nano column was $300 \mathrm{~nL} \mathrm{~min}{ }^{-1}$ and the solvent range from $7 \% \mathrm{~B}$ (5 min) to $35 \%$ (120 min). Solvent A was $0.1 \%$ formic acid in water whereas B was $0.1 \%$ formic acid in acetonitrile. The injection volume was $2 \mu \mathrm{L}$. The MS equipment has a high collision dissociation cell (HCD) for MS/MS experiments (fragmentation) and an Orbitrap analyzer (Q-ExactiveThermo Scientific Germany). A voltage of $3.5 \mathrm{kV}$ was used for Electro Spray Ionization (Thermo Scientific, EASY-SPRAY). XCalibur 3.0.63 (Thermo Scientific) software was used for data acquisition. The scanned mass range was $400-2000 \mathrm{~m} / \mathrm{z}$, at a resolution of 
70000 at $400 \mathrm{~m} / \mathrm{z}$ and the twelve most intense ions in each cycle, were sequentially isolated, fragmented by HCD and measured in the Orbitrap analyzer.

\section{Protein Digestion and LC-ESI-MS/MS Analysis}

Solution containing Ptr and Ub in PBS was incubated $1 \mathrm{~h}$ in the dark and irradiated. Then, the samples were enzymatically digested into smaller peptides using trypsin. Briefly, $10 \mu \mathrm{L}$ of trypsin $(500 \mathrm{ng})$ was added to $10 \mu \mathrm{L}$ of sample $(3.8 \mu \mathrm{g})$ and digestion was let overnight. The digestion was quenched with $2 \mu \mathrm{L}$ of $1 \%$ TFA. Subsequently, these peptides were analyzed using liquid chromatography coupled to tandem mass spectrometry (LC-MS/MS).

$1 \mu 1$ of sample was loaded onto a trap column (NanoLC Column, $3 \mu$ C18-CL, 350 $\mu \mathrm{m} \times 0.5 \mathrm{~mm}$; Eksigen) and desalted with $0.1 \%$ TFA at $3 \mu \mathrm{l} / \mathrm{min}$ during $5 \mathrm{~min}$. The peptides were then loaded onto an analytical column (LC Column, $3 \mu \mathrm{C} 18$-CL, $75 \mu \mathrm{m} \mathrm{x}$ $12 \mathrm{~cm}$, Nikkyo) equilibrated in 5\% acetonitrile $0.1 \% \mathrm{FA}$ (formic acid). Elution was carried out with a linear gradient of 5-95\% B in A for 30 min. (A: 0.1\% FA; B: ACN, 0.1\% FA) at a flow rate of $300 \mathrm{nl} / \mathrm{min}$. Peptides were analyzed in a mass spectrometer nanoESI qQTOF (5600 TripleTOF, ABSCIEX).

Sample was ionized applying $2.8 \mathrm{kV}$ to the spray emitter. Analysis was carried out in a data-dependent mode. Survey MS1 scans were acquired from 350-1250 m/z for $250 \mathrm{~ms}$. The quadrupole resolution was set to 'UNIT' for MS2 experiments, which were acquired $100-1500 \mathrm{~m} / \mathrm{z}$ for $50 \mathrm{~ms}$ in 'high sensitivity' mode. Following switch criteria were used: charge: $2+$ to $5+$; minimum intensity; 70 counts per second (cps). Up to 25 ions were selected for fragmentation after each survey scan. Dynamic exclusion was set to $15 \mathrm{~s}$. 
ProteinPilot v50. (ABSciex) search engine default parameters were used to generate peak list directly from 5600 TripleTOF wiff files. The obtained mgf was used for identification with MASCOT (v 2.5.1, Matrix- Science). Database search was performed on Expasy database (01.2018). Searches were done with tryptic specificity allowing one missed cleavage and a tolerance on the mass measurement of $25 \mathrm{ppm}$ in MS mode and 0.6 Da for MS/MS ions.

\section{Results}

\section{Photolysis in the absence of molecular oxygen}

As mentioned above, the generation of the photoadduct between pterin (Ptr) and substrates bearing thymine (Thy) only occurs in the absence of $\mathrm{O}_{2}$. In addition, in the case of proteins, this condition is also adequate to inhibit the formation of oxidation products from different amino acid residues, such as tyrosine (Tyr). ${ }^{18,32,33,34,35,36}$ Therefore, aqueous solutions containing Ptr and Ubiquitin (Ub) were irradiated at $350 \mathrm{~nm}$ under anaerobic conditions. As can be inferred from the corresponding absorption spectra (Figure 1), under these experimental conditions, Ptr was the only absorbing species. The experiments were performed at $\mathrm{pH} 6.0 \pm 0.1$, where Ptr is present at more than $99 \%$ in its acid form, ${ }^{37}$ that is the predominant form at physiological $\mathrm{pH}$. The photolyses were carried out at different $\mathrm{Ub}$ and Ptr concentrations (10-70 $\mu \mathrm{M}$ and 40-200 $\mu \mathrm{M}$, respectively) and for different periods of irradiation (up to $51 \mathrm{~J} . \mathrm{cm}^{-2}$ ).

The irradiated solutions were analyzed by chromatography with spectrophotometric and fluorescence detection (HPLC-PDA and HPLC-FL, respectively). The HPLC-PDA analysis showed that the concentration of Ptr decreased 
as a function of irradiation time, while the area corresponding to Ub slightly increased (Figure 2a). Chromatograms recorded at $350 \mathrm{~nm}$ (upper inset Figure 2a) showed that a new peak, with retention time $\left(t_{\mathrm{R}}\right)$ close to that corresponding to $\mathrm{Ub}$, appeared. The absorption spectra registered for this peak showed absorption in the UV-A (lower inset Figure 2a), which is compatible with the absorption features of pterins. ${ }^{37}$ The consumption of Ptr in the absence of Ub was significantly slower than in its presence (Figure 2b). HPLC-FL analysis showed the formation of a fluorescent product that emitted at $440 \mathrm{~nm}$ when excited at $350 \mathrm{~nm}$, which is consistent with the fluorescence properties of pterins. In addition, the $t_{\mathrm{R}}$ value of this product is equal, within the experimental error, to that of the intact protein and its area increased with irradiation time (Figure 2c). The irradiated solutions were also analyzed by electrophoresis (SDS-PAGE) and no changes in the electrophoretic mobility and in the concentration of $\mathrm{Ub}$ were observed as a function of irradiation time (Figure 3). In control experiments, a solution of Ub was exposed to UV-A radiation in the absence of Ptr. No change of the protein was detected by HPLC and spectral analyses, which is logical considering that it does not absorb at the excitation wavelength (Figure 1). 

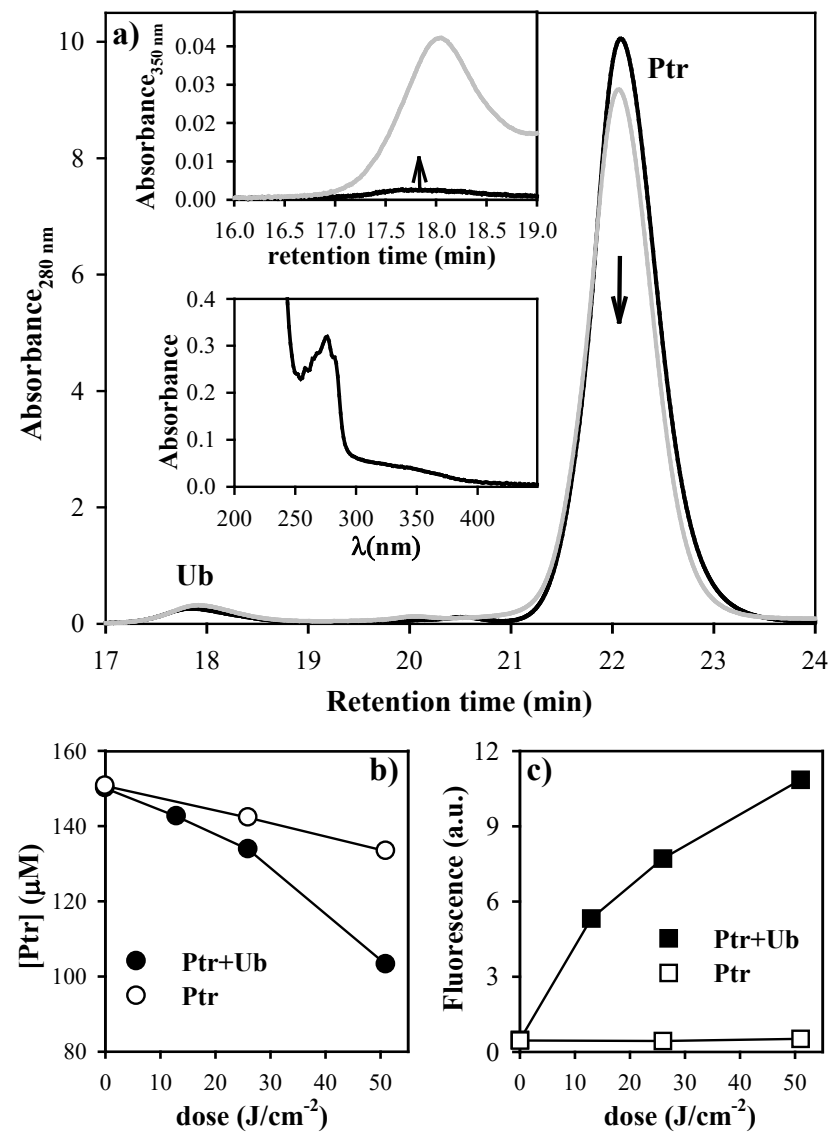

Figure 2. HPLC analysis of a solution (pH 6.0 \pm 0.1$)$ containing $\mathrm{Ub}(50 \mu \mathrm{M})$ and Ptr (150 $\mu M)$ irradiated under anaerobic conditions. a) HPLC-PDA analysis before (black line) and

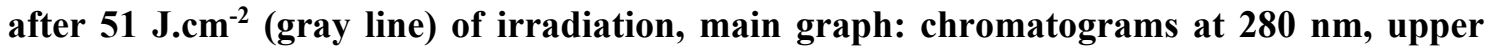
inset: chromatograms at $350 \mathrm{~nm}$, lower inset: absorption spectrum recorded at $t_{\mathrm{R}} 17.8 \mathrm{~min}$ from the irradiated sample run; b) time-evolution of the Ptr concentration; c) timeevolution of the area of the peak of the fluorescent product (HPLC-FL analysis, $\lambda_{\mathrm{exc}}=350$ $\left.\mathrm{nm}, \lambda_{\mathrm{em}}=440 \mathrm{~nm}\right)$.

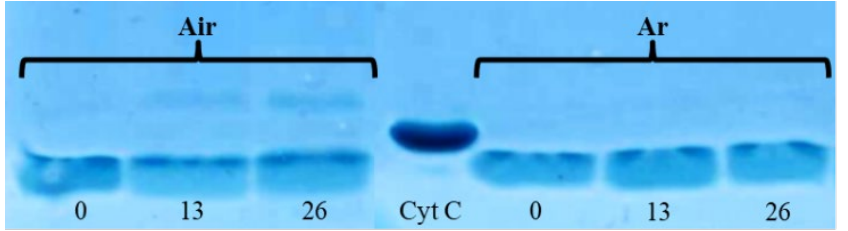

Figure 3. SDS-PAGE analysis of $\mathrm{Ub}(45 \mu \mathrm{M})$ solutions irradiated in the presence of Ptr (200 $\mu M)$ in air-equilibrated and in Ar-saturated solutions. The irradiation dose (J.cm-2) appears below each band. Cytochrome $\mathrm{C}(\mathrm{Cyt} \mathrm{C})$ was used as a molecular weight control.

To study the photophysical properties of the modified protein, the irradiated samples were purified by gel-filtration chromatography to eliminate the free Ptr. The 
fluorescence spectra of the protein fractions isolated from samples before and after irradiation were recorded by excitation at $350 \mathrm{~nm}$ (Figure 4a). The emission was negligible in non-irradiated solutions, confirming that the free Ptr was efficiently eliminated. On the other hand, in treated samples the emission increased with irradiation time, indicating that the photochemical process generates a fluorescent protein. The emission band presented a maximum at $430 \mathrm{~nm}$, which is very close to that of free Ptr (440 nm) (Figure 4a). Time-resolved experiments were carried out by excitation at 341 $\mathrm{nm}$ and the corresponding fluorescence decays of solutions irradiated for $51 \mathrm{~J} . \mathrm{cm}^{-2}$, recorded at $440 \mathrm{~nm}$ (Inset Figure 4a), were compatible with emission properties of Ptr. ${ }^{37}$ In addition, the fluorescence excitation spectrum of the protein fractions isolated from treated solutions was very similar to that corresponding to free Ptr (Figure 4b).

The results presented up to now suggest that, under anaerobic conditions, the photochemical process leads to the binding of Ptr to the protein to yield a fluorescent product. Since the chromatographic and electrophoretic mobilities of Ub are not altered by the irradiation in the presence of Ptr, it might be assumed that the protein does not undergo any chemical change, except the incorporation of the photosensitizer. The emission studies reveal that the adduct Ptr-Ub retains the fluorescence properties of Ptr. This behavior is similar to that described for the Ptr adducts in DNA. ${ }^{38}$

Thus, qualitative analysis of the photoproduct was carried out by Nanoscale liquid chromatography coupled to mass spectrometry (nano LC-MS) (material and methods). The ESI mass spectra of untreated samples, acquired using positive ion mode, showed the intact protein signals detected as $[\mathrm{M}+12 \mathrm{H}]^{12+}$ at $m / z=714.3957$ (Figure 5). Interestingly, in the irradiated samples an additional signal, which increases with irradiation time, appears at $m / z=727.8113$ with a pattern that matches with a $\mathrm{z}$ of 12 (Insets Figure 5). The difference between the ions corresponding to the intact $\mathrm{Ub}$ and the 
signal registered in the irradiated samples is $160.9872 \mathrm{Da}$, that is, the new signals correspond to the formula $[\mathrm{M}+\mathrm{Ptr}+10 \mathrm{H}]^{12+}$. These results confirm the formation of an adduct Ub-Ptr and reveal the loss of two hydrogen atoms in the reaction.
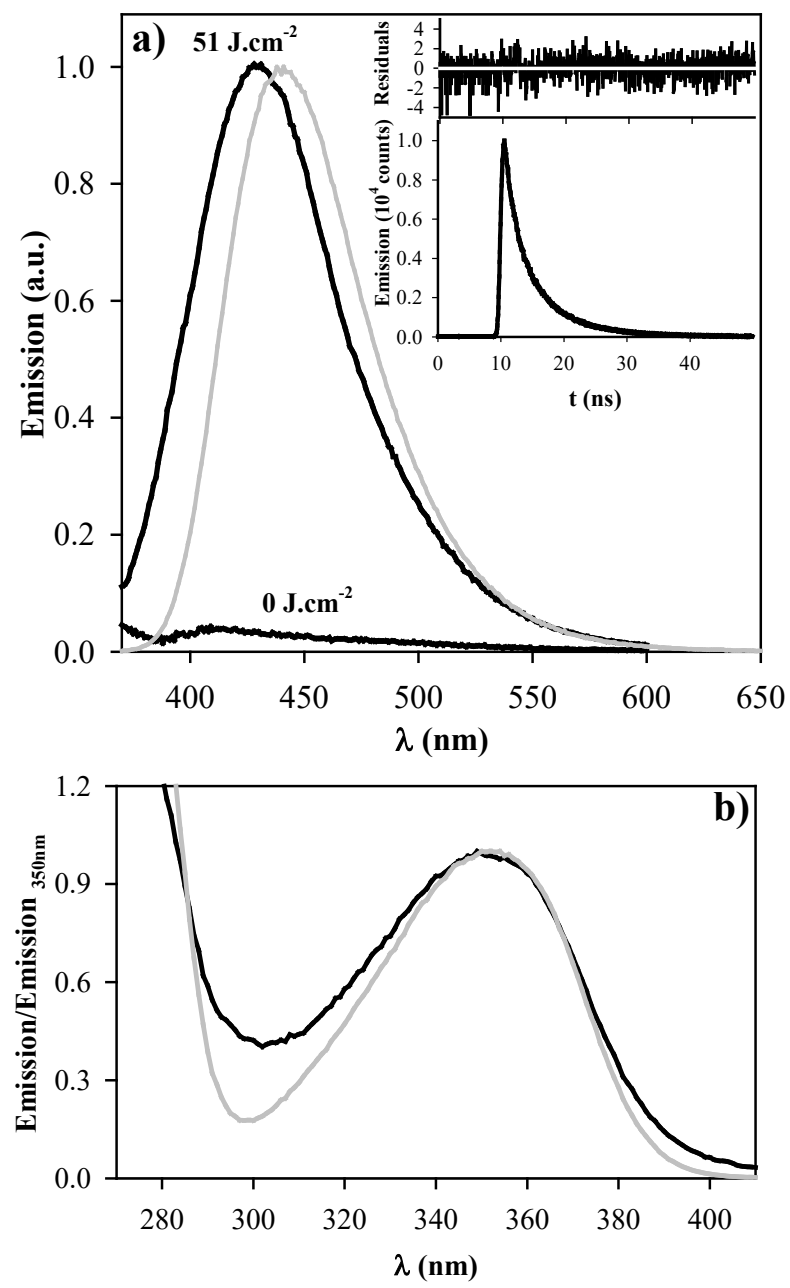

Figure 4. Fluorescence analysis of irradiated oxygen-free solutions $(\mathrm{pH}=6.0 \pm 0.1)$ of $\mathrm{Ub}(45$ $\mu \mathrm{M})$ and Ptr $(200 \mu \mathrm{M})$ after eliminating free Ptr by gel-filtration chromatography. a) Emission spectra obtained upon excitation at $350 \mathrm{~nm}$ before and after $51 \mathrm{J.cm}^{-2}$ of irradiation (black line) and emission spectrum of Ptr (gray line). Inset: Emission decay recorded at $440 \mathrm{~nm}\left(\lambda_{\text {exc }}=341 \mathrm{~nm}\right)$. b) Normalized excitation spectra $\left(\lambda_{\mathrm{em}}=440 \mathrm{~nm}\right)$ of isolated product (black line) and Ptr (gray line). 


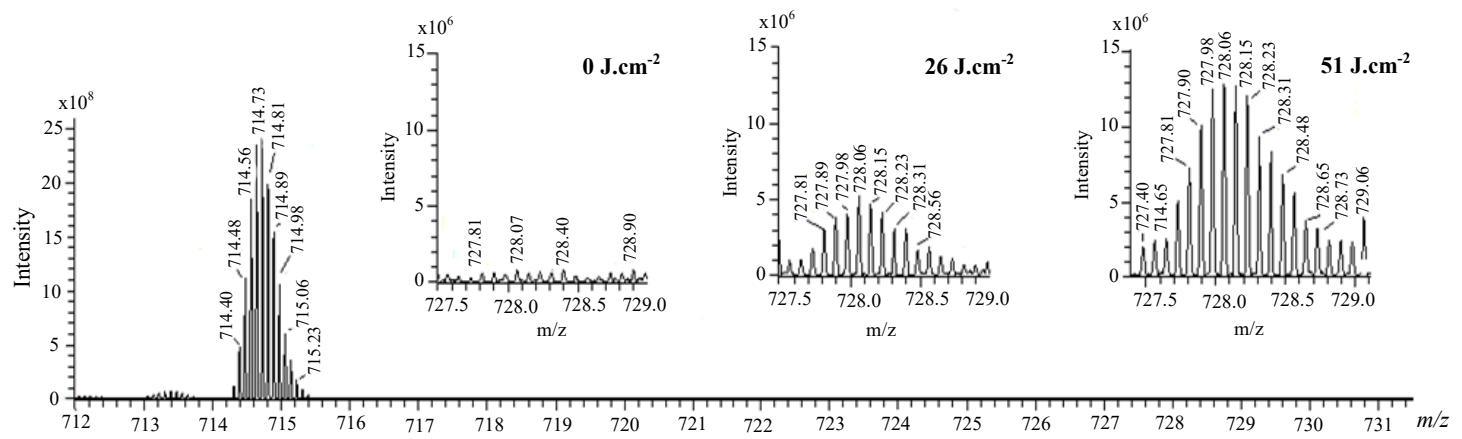

Figure 5: Nano LC-MS analysis. ESI mass spectra in positive ion mode of an Ar-equilibrated solution $(\mathrm{pH}=6.0 \pm 0.1)$ containing $\mathrm{Ub}(45 \mu \mathrm{M})$ and $\operatorname{Ptr}(200 \mu \mathrm{M})$ before irradiation. Inset: $\mathrm{m} / \mathrm{z}$ range: 727.0 to 729.0 before irradiation, after 26 and $51 \mathrm{J.cm}^{-2}$ of irradiation.

Further experiments were run in order to determine the potential location of the covalently bound Ptr. Thus, a sample of $\mathrm{Ub}(45 \mu \mathrm{M})$ and $\operatorname{Ptr}(150 \mu \mathrm{M})$ was exposed to UVA dose of $51 \mathrm{~J} \mathrm{~cm}^{-2}$ and enzymatically digested by trypsin to obtain small peptides cleaved at Arg and Lys sites. Next, HPLC-nanoESI was carried out in order to investigate the modified peptide sequence and to undertake a detailed characterization of the Ptrubiquitin adduct. The obtained data were analyzed by means of the Mascot ${ }^{\circledR}$ database search engine, and allowed the identification of two Ptr-ubiquitin derived peptide adducts: ${ }_{1}$ MQIFVKTLTGK $_{11}$ (that has one missed cleavage at Lys 6), ${ }_{64}$ ESTLHLVLR $_{72}$ (see data given in Table 1). Thus, the modification site of the peptides was assessed by tandem mass experiments on the trypsin digests. The MS/MS fragmentation was achieved by selecting the precursor ions given in Table 1. Both peptide sequence well agreed with the $y$ ion series. For fragment ${ }_{1}$ MQIFVKTLTGK 11 , the MS/MS fragment ions showed an unmodified $y$ ion series from $y 3$ to $y 5$, whereas an increment of $m / z 161 \mathrm{Ptr}(-2 \mathrm{H})$ was detected from $y 6$ to $y 10$ (see Figure S4a). Thus, the modified amino acid is the Lys 6. Examination of the other peptide, ${ }_{64} \mathrm{ESTLHLVLR}_{72}$ revealed that His can also be a site for the adduct formation with modifications detected at His 68. Diagnostic $y$ fragments $y 5$ to $y 8$ and $b$ fragments $b 5$ and $b 6$ with mass increment of 161 were detected (see Figure $\mathrm{S} 4 \mathrm{~b})$. 
Table 1. Data of Ptr modified peptides.

\begin{tabular}{lcccccc}
\hline Observed precursor ion $(\boldsymbol{m} / \mathbf{z})$ & Charge (z) & Mr (Exp) & Mr (calcd) & ppm & Sequence adduct site \\
\hline $\mathbf{4 7 6 . 2 5 9 7}$ & 3 & 1425.7573 & 1425.7551 & 2 & ${ }_{1} \mathrm{MQIFVK}^{\mathrm{Ptr}} \mathrm{TLTGK}_{11}$ \\
$\mathbf{4 1 0 . 2 2 4 2}$ & 3 & 1227.6508 & 1227.6472 & 3 & ${ }_{64} \mathrm{ESTLH}^{\mathrm{Ptr}} \mathrm{LVLR}_{72}$ \\
\hline
\end{tabular}

The results presented in this section clearly showed that under anaerobic conditions a Ptr-Ub adduct is formed and that the pterin moiety bound to the protein retains the spectroscopic properties of the free photosensitizer. The covalent bond takes place, at least, in two specific sites of the protein sequence: Lys 6 and His 68 . To the best of our knowledge, this is the first time that the photochemical covalent binding of a pterin derivative to a protein is reported.

\section{Photolysis in the presence of molecular oxygen}

To investigate if Ptr- $\mathrm{Ub}$ adduct is formed in the presence of $\mathrm{O}_{2}$, air-equilibrated aqueous solutions of $\mathrm{Ub}$ were exposed to UV-A radiation in the presence of Ptr and the treated solutions were analyzed by HPLC. The HPLC-PDA analysis (Figure 6) showed that upon irradiation the peak corresponding to the protein shifted to lower retention time and its area increased. The HPLC-FL analysis (Inset Figure 6, dashed line) showed a product, with a $t_{\mathrm{r}}$ value close to that of the protein, which emits at $440 \mathrm{~nm}$ upon excitation at $350 \mathrm{~nm}$, suggesting the incorporation of Ptr to the macromolecule. The concentration of Ptr decreased as a function of irradiation time, but, in this case the decrease was similar to that observed for the control carried out in the absence of Ub. 


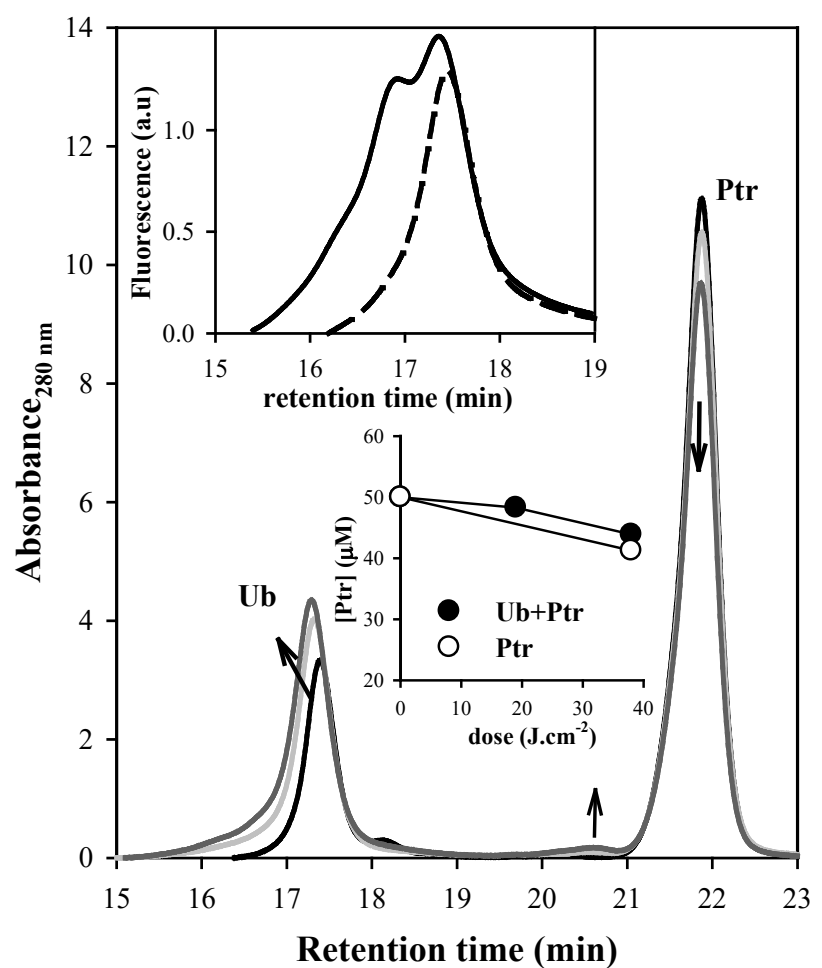

Figure 6. HPLC analysis of an air-equilibrated solution $(\mathrm{pH}=6.0 \pm 0.1)$ containing $\mathrm{Ub}(45$ $\mu \mathrm{M})$ and Ptr (45 $\mu \mathrm{M})$. HPLC-PDA analysis before (black line) and after 19 (light gray line) and $38 \mathrm{J.cm}^{-2}$ (dark gray line) of irradiation. Upper inset: HPLC-FL analysis of the solution

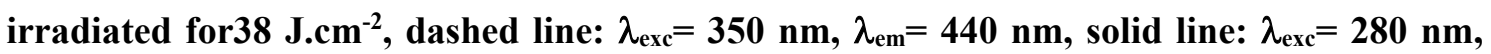
$\lambda_{\mathrm{em}}=410 \mathrm{~nm}$. Lower inset: time-evolution of Ptr concentration.

As in the case of experiments performed under anaerobic conditions, the protein fraction, at different irradiation times, was isolated by gel-filtration chromatography and its fluorescence properties were determined. The emission spectra and fluorescence lifetimes were similar to those of Ptr, suggesting that the fluorescent product corresponds to the Ptr-Ub adduct (Figure 7a). However, the excitation spectrum showed a maximum at ca. $350 \mathrm{~nm}$ similar to that of Ptr, together with a new band in the region of $290 \mathrm{~nm}$ (Figure $7 b$ ), indicating that another emitting component is present in this sample.

The results presented in this section so far showed that when an air-equilibrated solution of $\mathrm{Ub}$ is exposed to $\mathrm{UV}-\mathrm{A}$ radiation in the presence of Ptr a Ptr-Ub adduct is formed. This finding is surprising and relevant from a biomedical point of view because it demonstrates that dissolved oxygen does not prevent the binding of Ptr to a protein, as 
in the case of DNA. ${ }^{38}$
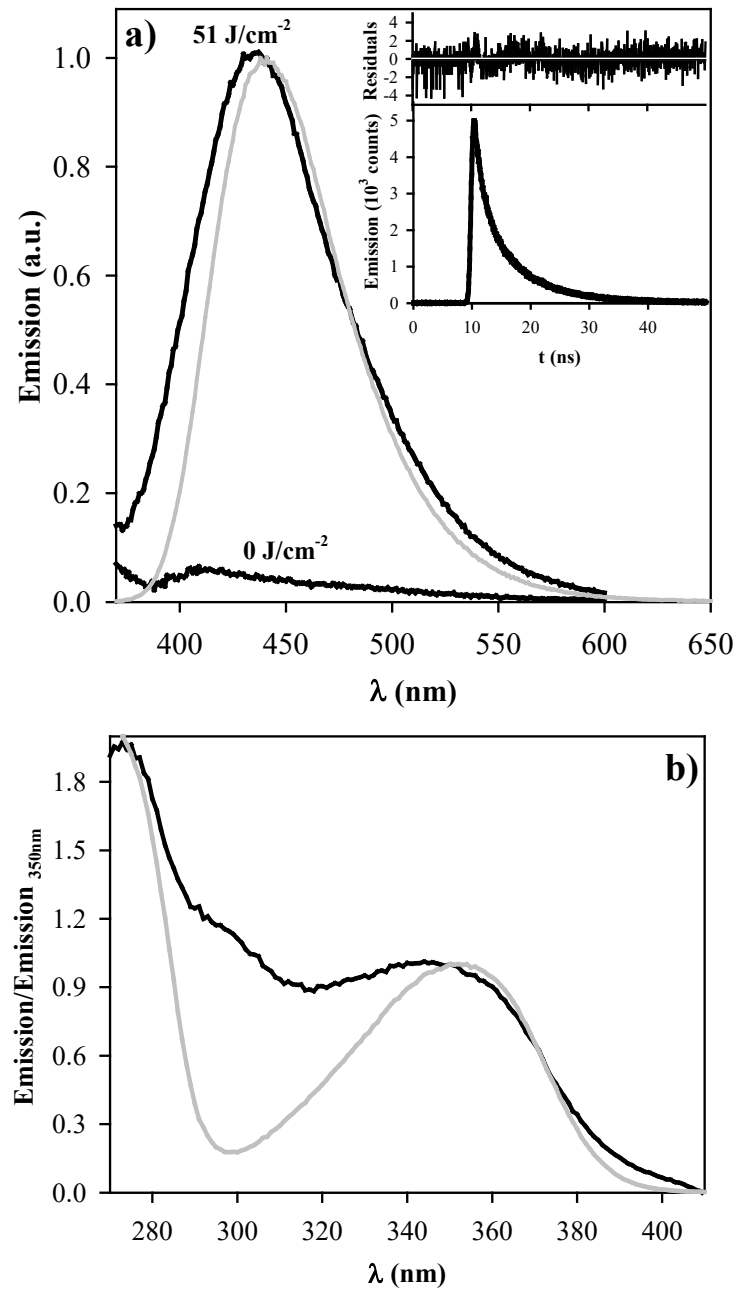

Figure 7. Fluorescence analysis of irradiated air-equilibrated solutions $(\mathrm{pH}=6.0 \pm 0.1)$ of Ub $(45 \mu \mathrm{M})$ and Ptr $(45 \mu \mathrm{M})$ after eliminating free Ptr by gel-filtration chromatography. a) Emission spectra obtained upon excitation at $350 \mathrm{~nm}$ before and after $51 \mathrm{J.cm}^{-2}$ of irradiation (black line) and emission spectrum of Ptr (gray line). Inset: Emission decay recorded at $440 \mathrm{~nm}\left(\lambda_{\text {exc }}=341 \mathrm{~nm}\right)$. b) Normalized excitation spectra $\left(\lambda_{\mathrm{em}}=440 \mathrm{~nm}\right)$ of isolated product (black line) and Ptr (gray line).

In this context, it has been reported that, in the presence of $\mathrm{O}_{2}, \mathrm{Ptr}$ is able to phototrigger the oligomerization of albumin through the formation of tyrosine dimer (Tyr2). ${ }^{18,23}$ Photophysical characterization of Tyr2, obtained from amino acid building blocks, established that, in acid aqueous solution, Tyr2 presents an absorption and emission maxima centered at ca. 280 and $410 \mathrm{~nm}$, respectively; ${ }^{39}$ which is in good accordance with the extra band observed in Figure 7. To investigate if $\mathrm{Tyr}_{2}$ is formed 
during this process, the irradiated solutions were analyzed by HPLC-FL using the conditions where $\mathrm{Tyr}_{2}$ emits $\left(\lambda_{\mathrm{exc}}=280 \mathrm{~nm}, \lambda_{\mathrm{em}}=410 \mathrm{~nm}\right)$ (Inset Figure 6). However, in this condition the Ptr-Ub photoadduct also emits. The HPLC-FL results showed that besides the peak corresponding to the $t_{\mathrm{R}}$ value of $\mathrm{Ub}$, a new peak at a $t_{\mathrm{R}}$ value of ca. 16.9 min appeared upon irradiation (Figure 6) and its area increased with irradiation time. Taking into account that we are using a size-exclusion column, the new peak corresponds to a product with higher molecular weight than $\mathrm{Ub}$, suggesting the formation of protein dimers. It is noteworthy that since Ub has only one Tyr residue, Ptr photosensitization would lead to the formation of dimers, but not to an oligomerization as in the case of albumin. ${ }^{23}$ It is also worth mentioning that the widening of the chromatographic peak, recorded under conditions in which the adduct is detected, suggests that a portion of the adducts are in the Ub dimer. This is logical if one assumes that formation of adduct and dimerization are independent processes. The electrophoretic patterns obtained in SDSPAGE analysis showed that a photoproduct with molecular weight corresponding to twice the molecular weight of Ub was formed (Figure 3).

In the experiments shown in Figure 6, besides the Ub-Ptr photoadduct and the dimer of $\mathrm{Ub}$, additional photoproducts with $t_{\mathrm{r}}$ values between those corresponding to $\mathrm{Ub}$ and Ptr were observed. Although the peaks of these products were small in the concentration conditions of the experiment of Figure $6([\mathrm{Ptr}]=45 \mu \mathrm{M})$, they turned out to be much bigger when the concentration of the photosensitizer was higher. That is the case of the experiment shown in Figure 8, in which $200 \mu \mathrm{M}$ of Ptr was used. In addition, in contrast to that observed in Figure 6, a decrease in the peak corresponding to Ub and its dimer was observed. These results suggest that in the presence of oxygen, a fragmentation of the protein takes place and that the process is relatively more important at higher 
concentration of photosensitizer. To the best of our knowledge, it is the first time that the cleavage of a protein caused by photosensitization with a pterin derivative is observed.

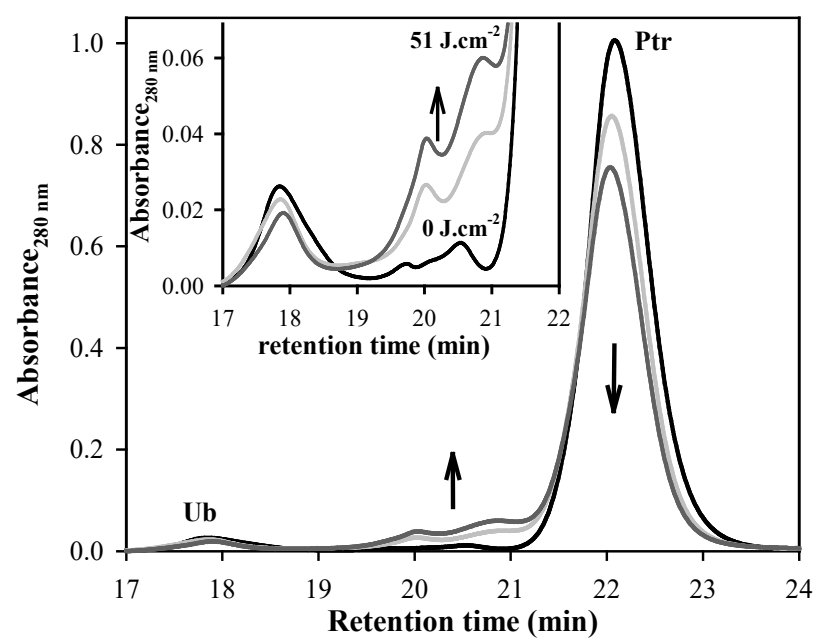

Figure 8. HPLC-PDA analysis of an air-equilibrated solution $(\mathrm{pH}=6.0 \pm 0.1)$ containing $\mathrm{Ub}$ $(45 \mu \mathrm{M})$ and Ptr $(200 \mu \mathrm{M})$ before (black line) and after 26 (light gray line) and $51 \mathrm{J.cm}^{-}$ ${ }^{2}$ (dark gray line) of irradiation.

To further investigate the photoproducts of the photochemical processes, airequilibrated solutions of $\mathrm{Ub}$ and Ptr were analyzed by mass spectrometry using nano LCMS. Mass spectra of irradiated samples showed oxidized products with signals at $m / z=$ $716.0585\left([\mathrm{M}+\mathrm{O}+12 \mathrm{H}]^{12+}\right), \quad m / z=718.8092\left([\mathrm{M}+3 \mathrm{O}+12 \mathrm{H}]^{12+}\right), \quad m / z=720.1422$ $\left([\mathrm{M}+4 \mathrm{O}+12 \mathrm{H}]^{12+}\right)$, and $m / z=721.3905\left([\mathrm{M}+5 \mathrm{O}+12 \mathrm{H}]^{12+}\right)$ (Figure 9a), indicating the incorporation of one to five oxygen atoms to Ub protein $[\mathrm{M}]$. None of these signals was detected in the non-irradiated solution (Figure S2a). This group of products was expected taking into account previous studies. ${ }^{18}$ In addition, some smaller products appeared with exact mass of 5514.24 Da and 5597.60 Da, detected as ionic species at $m / z=690.2565$ $(\mathrm{z}=8)$ and at $m / z=700.7651(\mathrm{z}=8)$, respectively (Figure $9 \mathrm{~b})$. Another signal was observed at $m / z=688.1544(\mathrm{z}=9)$, corresponding to mass $=6184.35 \mathrm{Da}$. None of these signals was detected in the non-irradiated solution or in the Ar-saturated solution after irradiation 
(Figures S3a and S3b, respectively). This analysis confirmed the fragmentation of the protein upon UVA irradiation in the presence of Ptr.
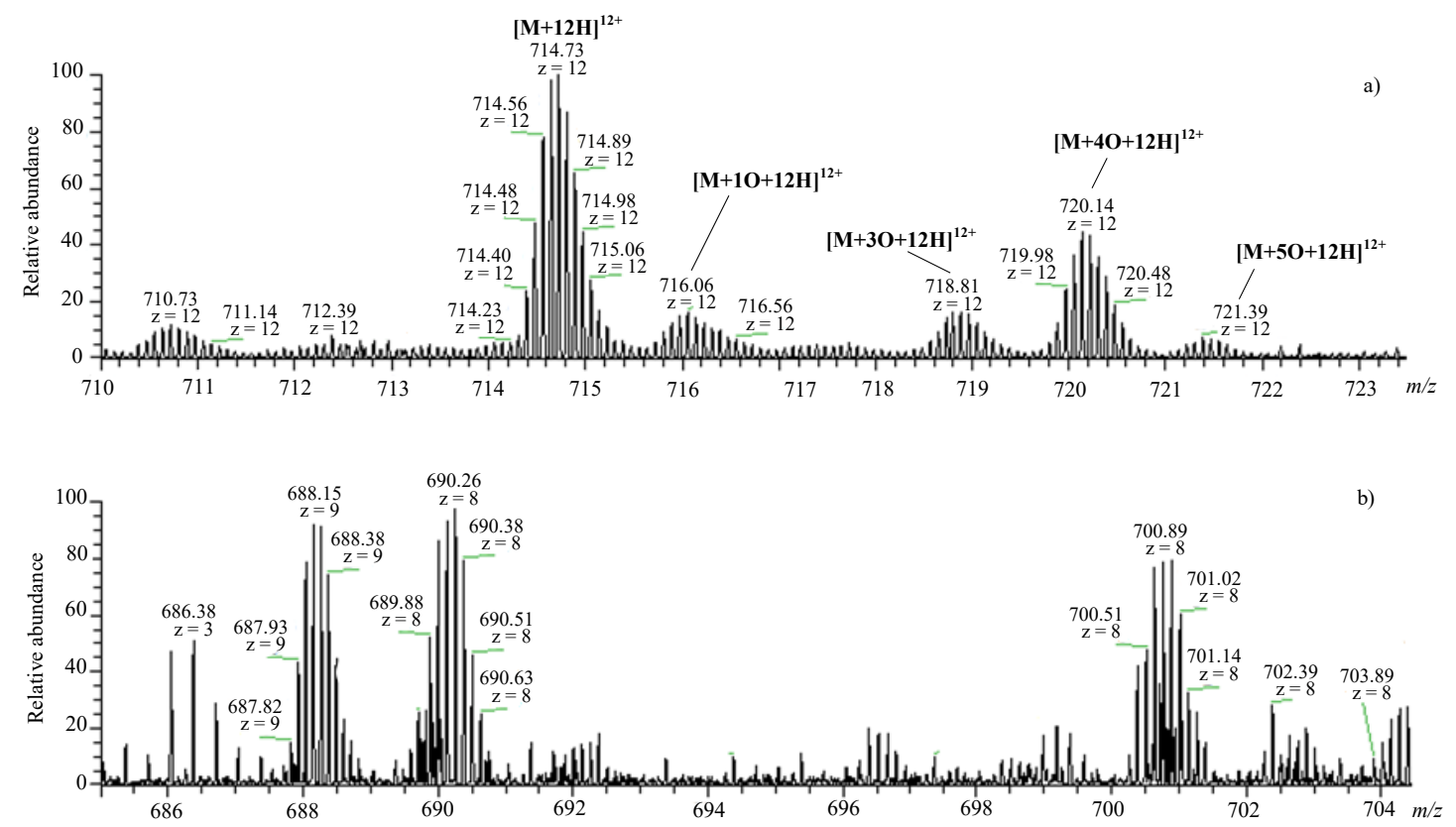

Figure 9. Nano LC-MS analysis. ESI mass spectra in positive ion mode of air-equilibrated

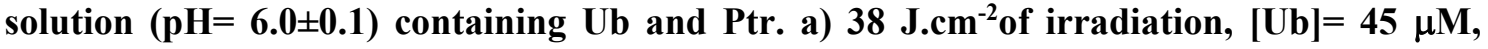

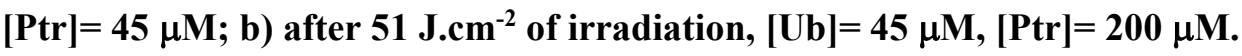

Due to the complexity of the reaction system that led to a mix of many photoproducts, additional analyses were performed by Matrix-Assisted Laser Desorption - Ionization-Time of Flight Mass Spectrometry (MALDI-TOF-MS, Experimental Section). Mass spectra obtained for samples before irradiation showed the signal corresponding to $\mathrm{Ub}$ as a narrow peak at $m / z=8565.99\left([\mathrm{M}+\mathrm{H}]^{+}\right)$and as a peak with low $\mathrm{S} / \mathrm{N}$ ratio at $m / z=4283.34\left([\mathrm{M}+2 \mathrm{H}]^{2+}\right)$ (Figure 10a). Upon irradiation, the peak corresponding to $\mathrm{Ub}\left([\mathrm{M}+\mathrm{H}]^{+}\right)$broadened indicating the formation of some photoproducts with a molecular weight slightly different from that of Ub (Figure 10b), which is in agreement with the oxidized products detected by nano LC-MS. Additionally, intense signals were detected in the $m / z$ range 5400-5600 (Figure 10b), consistent with the fragmentation of the protein. Moreover, it is worth noting, that difference between 
peaks at $m / z=5499.51$ and $m / z=5515.12$, but also between those at $m / z=5582.47$ and $m / z=5598.63$ is $\Delta m / z=16$, suggesting that one oxygen atom is added during the photochemical reaction.

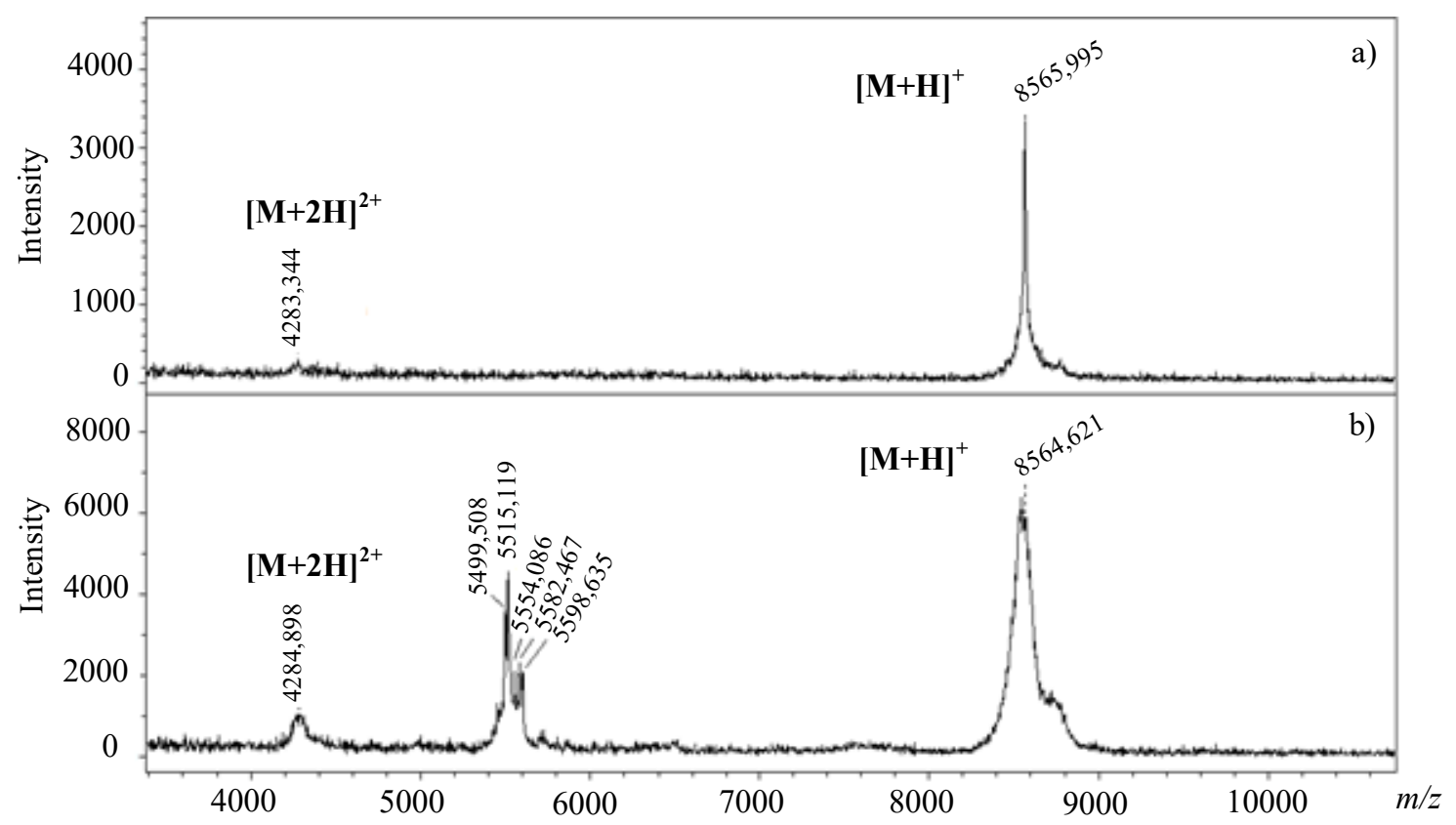

Figure 10. MALDI-TOF-MS analysis. Mass spectra in positive ion mode of an airequilibrated solution ( $\mathrm{pH}=6.0 \pm 0.1)$ containing $\mathrm{Ub}(45 \mu \mathrm{M})$ and Ptr $(45 \mu \mathrm{M})$ obtained with MALDI, a) before irradiation, b) after $38 \mathrm{J.cm}{ }^{-2}$ of irradiation. Matrix: SA.

Both formation of oxygenated products and dimerization were expected taking into account previous studies. Both processes can be classified as type I photosensitized oxidation and are initiated by an electron transfer from a given oxidizable amino acids, such as Tyr, to the triplet excited state of $\operatorname{Ptr}\left({ }^{3} \operatorname{Ptr}^{*}\right)$ (Reaction 3). The radical cation of the substrate can undergo deprotonation (Reaction 4). These radicals can yield oxygenated products (Reaction 5) or a dimer (Reaction 6). Ptr is recovered in the process because its radical anion reacts with dissolved oxygen (Reaction 7). This typical type I reaction scheme has been proven in several subtrates ${ }^{18,23,39}$

$$
\begin{array}{r}
{ }^{3} \mathrm{Ptr}^{*}+\mathrm{Tyr} \longrightarrow \operatorname{Ptr}^{\bullet-}+\mathrm{Tyr}^{\bullet+} \\
\mathrm{Tyr}^{\cdot+} \longrightarrow \operatorname{Tyr}(-\mathrm{H})^{\bullet}+\mathrm{H}^{+}
\end{array}
$$




$$
\begin{aligned}
\operatorname{Tyr}^{\bullet+} / \operatorname{Tyr}(-\mathrm{H})^{\bullet}+\mathrm{O}_{2} / \mathrm{O}_{2}{ }^{-} & \longrightarrow \operatorname{Tyr}(\mathrm{ox}) \\
2 \mathrm{Tyr}(-\mathrm{H})^{\bullet} & \longrightarrow \operatorname{Tyr}_{2} \\
\mathrm{Ptr}^{-}+\mathrm{O}_{2} & \longrightarrow \operatorname{Ptr}+\mathrm{O}_{2}{ }^{-}
\end{aligned}
$$

\section{Conclusions}

Ubiquitin (Ub) damage photoinduced by the natural photosensitizer pterin (Ptr) in aqueous solution under UV-A irradiation was investigated. Under anaerobic conditions the photosensitizer reacts with $\mathrm{Ub}$ to form a Ptr-Ub adduct that retains the spectroscopic properties of the free photosensitizer and in which the Ptr moiety becomes covalently bound to the protein. Three different chemical processes take place in air-equilibrated solutions: formation of a Ptr-Ub adduct, dimerization and fragmentation of the protein.

The fact that the Ptr-Ub adduct is formed even in the presence of oxygen is relevant from a biomedical point of view because it suggests that, under pathological situations in which Ptr and other oxidized pterin derivatives accumulate in the skin, it is likely that adducts with proteins are formed upon exposure to natural or artificial sources of UV radiation. In contrast, dimerization was expected taking into account previous studies. Finally, the fragmentation of the protein was an unexpected result that deserves further investigation.

\section{Acknowledgements}


The present work was partially supported by Consejo Nacional de Investigaciones Científicas y Técnicas (CONICET-Grants PIP 112-200901-0304 and PIP 11220120100072CO), Agencia de Promoción Científica y Tecnológica (ANPCyTGrants PICT-2015-1988 and PICT 2016-00130), Universidad Nacional de La Plata (UNLP-Grant X712 and X840), Universidad de Buenos Aires (UBA-Grant 000110BA). Funding from the Programa CSIC de Cooperación Científica para el Desarrollo (iCOOPLight project ref 20105CD0017) and Spanish government (PGC2018-096684-BI00) are gratefully acknowledged. The Ultraflex II (Bruker) TOF/TOF mass spectrometer was supported by a grant from ANPCYT, PME2003 No.125 and the ESI-MS Q Exactive, Thermo Scientific, by a grant from ANPCYT, PME2011- PPL2-0009, CEQUIBIEM, DQB, FCEN, UBA). The proteomic analysis was performed in the proteomics facility of SCSIE University of Valencia. This proteomics laboratory is a member of Proteored, PRB3 and is supported by grant PT17/0019, of the PE I+D+i 2013-2016, funded by ISCIII and ERDF. L.O.R. thanks CONICET for doctoral research fellowships. R.E-B, G.P., M.L.D. and A.H.T are research members of CONICET.

\section{References}

(1) Montaro, S.; Lhiaubet-Vallet, V.; Jiménez, M. C.; Blanca, M.; Miranda, M. A. (2009) Photonucleophilic addition of the $\varepsilon$-amino group of lysine to a triflusal metabolite as a mechanistic key to photoallergy mediated by the parent drug. ChemMedChem 4, 11961202.

( 2 ) Harber, L. C.; Baer, R. (1972) Pathogenic mechanisms of drug-induced photosensitivity. J. Invest. Dermatol. 58, 327-342.

(3) Honari, G. (2014) Photoallergy, Rev. Environ. Health 29, 233-242. 
(4) Glatz, M.; Hofbauer, G. F. L. (2012) Phototoxic and photoallergic cutaneous drug reactions. Chem. Immunol. Allergy. 97, 167-179,

(5) Nuin, E.; Pérez-Sala, D.; Lhiaubet-Vallet, V.; Andreu, I.; Miranda, M. A. (2016)

Photosensitivity to triflusal: formation of a photoadduct with ubiquitin demonstrated by photophysical and proteomic techniques. Front. Pharmacol. 7, 1-8,

(6) Pfleiderer W. In: Chemistry and Biology of Pteridines and Folates, Ayling J. E., Nair M. G., Baugh C. M., eds. New York Plenum Press. 1993: 1-16.

(7) Kappock, T. J.; Caradonna, J. P. (1996) Pterin-dependent amino acid hydroxylases. Chem. Rev. 96, 2659-2756.

(8) Ziegler, I. (1990) Production of pteridines during hematopoiesis and T-lymphocyte proliferation:potential participation in the control of cytokine signal transmission. Med. Res. Rev. 10, 95-114.

(9) Schallreuter, K. U.; Wood J. M.; Pittelkow, M. R.; Gütlich, M.; Lemke, K. R.; Rödl, W.; Swanson, N. N.; Hitzemann, K.; Ziegler, I. (1994) Regulation of melanin biosynthesis in the human epidermis by tetrahydrobiopterin. Science.; 263: 1444-1446. (10) Glassman, S. J. (2010) Vitiligo, reactive oxygen species and T-cells. Clin. Sci. 120, 99-120.

(11) Schallreuter, K.U.; Moore, J.; Wood, J. M.; Beazley, W. D.; Peters, E. M.; Marles, L. K.; Behrens-Williams, S.C.; Dummer, R.; Blau, N.; Thöny, B. (2001) Epidermal $\mathrm{H}_{2} \mathrm{O}_{2}$ accumulation alters tetrahydrobiopterin $(6 \mathrm{BH} 4)$ recycling in vitiligo: Identification of a general mechanism in regulation of all 6BH4-dependent processes?, J. Invest. Dermatol. $116,167-174$.

(12) Rokos, H.; Beazley, W. D.; Schallreuter, K. U. (2002) Oxidative stress in vitiligo: photo- oxidation of pterins produces $\mathrm{H}_{2} \mathrm{O}_{2}$ and pterin-6-carboxylic acid. Biochem. Biophys. Res. Commun. 292; 805-811. 
(13) Thomas, A. H.; Catalá, A.; Vignoni, M. (2016) Soybean phosphatidylcholine liposomes as model membranes to study lipid peroxidation photoinduced by pterin. Biochim. Biophys. Acta Biomembr. 1858, 139-145.

(14) Neverov, K.V.; Mironov, E. A.; Lyudnikova, T. A., Krasnovsky Jr., A. A.; Kritsky, M. S. (1996) Phosphorescence analysis of the triplet state of pterins in connection with their photoreceptor function in biochemical systems. Biochemistry (Moscow) 61, 11491155.

(15) Egorov, S.Y.; Krasnovsky Jr,. A.A.; Bashtanov, M.Y.; Mironov, E. A.; Ludnikova, T. A.; Kritsky, M. S. (1999) Photosensitization of singlet oxygen formation by pterins and flavins. Time-resolved studies of oxygen phosphorescence under laser excitation. Biochemistry (Moscow) 64, 1117-1121.

(16) Oliveros, E.; Dántola, M. L.; Vignoni, M.; Thomas, A. H.; Lorente, C. (2011) Production and quenching of reactive oxygen species by pterin derivatives, an intriguing class of biomolecules. Pure Appl. Chem. 83, 801-811.

(17) Serrano, M. P.; Estébanez, S.; Vignoni, M.; Lorente, C.; Vicendo, P.; Oliveros, E.; Thomas, A. H. (2017) Photosensitized oxidation of 2'-deoxyguanosine 5'monophosphate: mechanism of the competitive reactions and product characterization. New J. Chem. 41, 7273-7282.

(18) Dántola, M. L.; Reid, L. O.; Castaño, C.; Lorente, C.; Oliveros, E.; Thomas, A. H. (2017) Photosensitization of peptides and proteins by pterin derivatives. Pteridines, 28, 105-114.

(19) Vignoni, M.; Urrutia, M. N.; Junqueira, H. C.; Greer, A.; Reis, A.; Baptista, M. S.; Itri, R.; Thomas, A. H. (2018) Photooxidation of unilamellar vesicles by a lipophilic pterin: Deciphering biomembrane photodamage. Langmuir 34. 15578-15586. 
( 20 ) Estébanez, S.; Thomas, A. H.; Lorente, C. (2018) Deoxythymidine-pterin fluorescent adduct formation through a photosensitized process, ChemPhysChem 19, $300-306$.

(21) Serrano, M. P.; Vignoni, M.; Lorente, C.; Vicendo, P.; Oliveros, E.; Thomas, A. H. (2016) Thymidine radical formation via one-electron transfer oxidation photoinduced by pterin: Mechanism and products characterization. Free Radic. Biol. Med. 96, 418-431.

(22) Dántola, M. L.; Zurbano, B. N.; Thomas, A. H. (2015) Photoinactivation of tyrosinase sensitized by folic acid photoproducts J. Photochem. Photobiol. B Biol. 149, $172-179$.

(23) Reid, L. O.; Roman, E. A.; Thomas, A. H.; Dántola, M. L. (2016) Photooxidation of tryptophan and tyrosine residues in human serum albumin sensitized by pterin: a model for globular protein photodamage in skin. Biochemistry 55, 4777-4786.

(24) Pickart, C. M.; Eddins, M. J. (2004) Ubiquitin: structures, functions, mechanisms, Biochim. Biophys. Acta Mol. Cell. Res. 1695, 55-72.

(25) Hochstrasser, M. (2009) Origin and function of ubiquitin-like proteins. Nature 458, $422-429$

(26) Jeram, S. M.; Srikumar, T.; Pedrioli, P. G. A.; Raught, B. (2009) Using mass spectrometry to identify ubiquitin and ubiquitin-like protein conjugation sites. Proteomics 9, 922-934.

(27) Hong, J. H.; Ng, D.; Srikumar, T.; Raught, B. (2015) The use of ubiquitin lysine mutants to characterize E2-E3 likage specificity: Mass spectrometry offers a cautionary “tail". Protemics 15, 2910-2915.

(28) Braslavsky S. E. (2007) Glossary of terms used in photochemistry, 3rd edition (IUPAC Recommendations 2006). Pure Appl. Chem. 79, 293-465. 
(29) Kuhn H. J.; Braslavsky, S. E.; Schmidt, R. (2004) Chemical actinometry (IUPAC technical report). Pure Appl. Chem. 76, 2105-2146.

(30) Serrano, M. P.; Vignoni, M.; Dántola, M. L.; Oliveros, E.; Lorente, C.; Thomas, A. H. (2011) Emission properties of dihydropterins in aqueous solutions. Phys. Chem. Chem. Phys. 13, 7419-7425.

(31) Nonami, H.; Fukui, S.; Erra-Balsells. R. (1997) $\beta$-Carboline alkaloids as matrices for matrix-assisted ultraviolet laser desorption time-of flight mass spectrometry of proteins and sulfated oligosaccharides: a comparative study using phenylcarbonyl compounds, carbazoles and classical matrices. J. Mass Spectrom. 32, 287-296.

(32) Silva, E.; Godoy, J. (1994) Riboflavin Sensitized photooxidation of tyrosine. Internat J. Vit. Nutr. Res. 64, 253-256.

(33) Dalsgaard, T. K.; Nielsen, J. H.; Brown, B. E.; Stadler, N.; Davies, M. J. (2011) Dityrosine, 3,4-dihydroxyphenylalanine (DOPA), and radical formation from tyrosine residues on milk proteins with globular and flexible structures as a result of riboflavinmediated photo-oxidation. J. Agric. Food Chem. 59, 7939-7947

(34) Pattison, D. I.; Suryo Rahmantoa, A.; Davies, M. J. (2012) Photo-oxidation of protein. Photochem. Photobiol. Sci. 11, 38-53.

(35) Michaeli, A.; Feitels, J. (1994) Reactivity of singlet oxygen toward amino acids and peptides. Photochem. Photobiol. 59, 284-289.

(36) Rizzuto, F.; Spike, J. D. (1977) The eosin-sensitized photooxidation of substituted phenylalanines and tyrosines. Photochem. Photobiol. 25, 465-476.

(37) Lorente, C.; Thomas, A. H. (2006) Photophysics and photochemistry of pterins in aqueous solution. Acc. Chem. Res. 39, 395-402. 
(38) Estébanez, S.; Lorente, C.; Gaspar Tosato, M.; Miranda, M. A.; Marín, M. L.; Lhiaubet-Vallet, V.; Thomas, A. H. (2019) Photochemical formation of a fluorescent thymidine-pterin adduct in DNA. Dyes Pigm. 160, 624-632.

(39) Reid, L. O.; Castaño, C.; Dántola, M. L.; Lhiaubet-Vallet, V.; Miranda, M. A.; Marin, M. L.; Thomas, A. H. (2017) A novel synthetic approach to tyrosine dimers based on pterin photosensitization, Dyes Pigm. 147, 67-74. 
